\title{
Usos de vírgulas em textos do início do Ensino Fundamental II: distribuição e evidências de características prosódicas
}

\author{
Tainan Garcia Carvalho \\ Universidade Estadual Paulista "Júlio de Mesquita Filho" (UNESP), \\ São José do Rio Preto, São Paulo, Brasil \\ tainan.garcia@hotmail.com \\ https://orcid.org/0000-0001-6105-3120
}

DOI: http://dx.doi.org/10.21165/el.v47i2.2004

\begin{abstract}
Resumo
O objetivo deste artigo é descrever e analisar usos convencionais e não-convencionais de vírgulas de uma amostra longitudinal de textos produzidos por 94 sujeitos no ciclo inicial $\left(6^{\circ} \mathrm{e}\right.$ $7^{\circ}$ anos) do Ensino Fundamental II de uma escola pública de São José do Rio Preto. Os textos pertencem ao Banco de Dados de Escrita do Ensino Fundamental II (TENANI; LONGHINTHOMAZI, 2014). Ao partirmos da hipótese de que os usos de vírgulas estão associados a características prosódicas do Português Brasileiro, buscaremos descrever algumas das características prosódicas mais relevantes identificadas nas fronteiras de usos de vírgulas. Para tanto, a metodologia consiste na interface entre estruturas sintáticas, levantadas a partir das normas prescritas em Bechara (1999), e estruturas fonológicas, com base no arcabouço teórico da Fonologia Prosódica (NESPOR; VOGEL, 1986).
\end{abstract}

Palavras-chave: escrita; empregos de vírgulas; prosódia; pontuação; fonologia.

Uses of commas in the beginning of Junior High School: distribution and evidences of prosodic characteristics

\begin{abstract}
The purpose of this article is to describe and to analyze formal and non-formal uses of commas of a longitudinal sample of texts produced by 94 students in the initial cycle $\left(6^{\text {th }}\right.$ and $7^{\text {th }}$ years) of Junior High School of a public school in São José do Rio Preto. The texts belong to the Banco de Dados de Escrita do Ensino Fundamental II (TENANI; LONGHIN-THOMAZI, 2014). Based on the hypothesis that comma uses are associated to prosodic characteristics of Brazilian Portuguese, we will try to describe the most relevant prosodic characteristics identified in the borders of comma uses. For this, the methodology consists on the interface between syntactic structures, raised from the rules prescribed in Bechara (1999), and the phonological structures based on the Prosodic Phonology framework (NESPOR; VOGEL, 1986).
\end{abstract}

Keywords: writing; Comma uses; prosody; punctuation; phonology.

\section{Introdução}

Neste artigo, apresentamos os resultados obtidos em uma pesquisa (FAPESP Proc. 2015/15289-1) acerca dos usos convencionais e não-convencionais de vírgulas de uma amostra longitudinal de produções textuais do $6^{\circ}$ e do $7^{\circ}$ anos letivos considerados por nós como ciclo inicial do Ensino Fundamental II (doravante, EFII). 
Enquanto sinal de pontuação, podemos afirmar que a vírgula é um dos sinais que gera mais controvérsias a respeito de seu uso e funcionamento, haja vista sua natureza constitutivamente complexa. Essa complexidade é reafirmada por diversos fatores, entre eles: (i) a falta de unanimidade entre os gramáticos quanto às regras de seu emprego; (ii) seu funcionamento sintático ora em esquema simples $(/, /)$, ora em esquema duplo $(/,, /)$, ou ainda, nas amplitudes intercláusula e intracláusula (DAHLET, 2006) e (iii) a veiculação corrente de discursos de que vírgulas são "pausas para respirar" e/ou "sinais gráficos que reproduzem aspectos da fala na escrita".

Somada a essa complexidade e instabilidade características desse sinal de pontuação, destacamos também questões relacionadas ao ensino de vírgulas em contexto escolar. De uma perspectiva tradicional escolar, o ensino de vírgulas é orientado principalmente pelo (re)conhecimento de regras sintáticas de seu uso. Em contrapartida, o trabalho sistematizado com os sinais de pontuação é previsto apenas para as séries finais do EF II, não sendo, portanto, tema central para as séries iniciais, de acordo com informações contidas na Proposta Curricular do Estado de São Paulo (2008). Frente a esse cenário, a hipótese central deste trabalho parte da premissa de que os usos de vírgulas em textos do ciclo inicial do EFII estão relacionados a aspectos linguísticos de natureza prosódica. Cabe ressaltar, no entanto, que esta relação entre pontuação e prosódia não é entendida, neste trabalho, como vinculada ao ensino formal de vírgulas, mas sim marcada pela própria constituição histórica da pontuação, haja vista que, na antiguidade, o sistema de pontuação surge como mecanismo de representação da prosódia da fala no texto escrito. Dessa forma, tendo no horizonte esta hipótese, nosso objetivo consiste em descrever e analisar algumas das características prosódicas mais relevantes identificadas em fronteiras sintáticas de usos de vírgulas.

No que tange à organização deste artigo, apresentamos, inicialmente, os pressupostos teóricos nos quais nos amparamos para a realização desta pesquisa, seguidos da caracterização do material selecionado e dos procedimentos metodológicos adotados na análise. Na sequência, fornecemos uma análise quantitativa dos contextos sintáticos para os quais houve mais evidências de empregos convencionais e nãoconvencionais de vírgulas nos textos do ciclo inicial do EFII. Por fim, com base em um texto representativo das tendências de emprego de vírgulas, propomos uma análise qualitativa de base prosódica com a finalidade de evidenciar domínios prosódicos relacionados às fronteiras em que há evidências de emprego de vírgulas.

\section{Pressupostos teóricos}

Partindo da concepção de que a análise dos usos de vírgulas constitui um lugar privilegiado de observação das relações estabelecidas pelos sujeitos-escreventes entre fala e escrita, amparamo-nos em um arcabouço teórico que abrange: (i) os conceitos de ritmo da escrita (CHACON, 1998), multidimensionalidade da linguagem (CHACON, 1998; ESVAEL, 2005) e a noção de heterogeneidade constitutiva da escrita (CÔRREA, 2004) e (ii) os domínios prosódicos definidos pelo modelo da Fonologia Prosódica (NESPOR; VOGEL, 1986).

De uma perspectiva tradicional escolar, a vírgula configura-se, por um lado, como sinal gráfico que representa pausas respiratórias na escrita. Em contrapartida, 
nesse mesmo contexto escolar, emerge também o discurso de que saber empregar vírgulas é equivalente a conhecer/ter domínio das regras sintáticas de seu uso. Visivelmente, há contradição no modo como o ensino de pontuação é orientado: ora o critério é respiratório; ora, sintático. Neste trabalho, nos distanciamos dessa perspectiva institucional escolar ao considerarmos os usos de vírgulas enquanto marcas gráficas privilegiadas para a observação do ritmo da escrita (CHACON, 1998) e do funcionamento linguístico desse sinal em várias dimensões da linguagem (CHACON, 1998; ESVAEL, 2005).

De acordo com Chacon (1998), fala e escrita apresentam ritmos próprios, porém não dissociados: enquanto o ritmo da fala é temporalmente delimitado, o ritmo da escrita é espacialmente delimitado. Para o autor, os sinais de pontuação funcionam como mecanismo responsável por organizar e atribuir um ritmo próprio à escrita, pois simultaneamente delimitam e integram sequências gráfico-espaciais. Além disso, a pontuação é uma organização que, embora de natureza gráfica e espacial, é constituída por características da organização temporal dos enunciados falados. Na perspectiva de Chacon (1998), o modo pelo qual este ritmo da escrita torna-se evidente é na atuação dos sinais de pontuação em quatro dimensões da linguagem: dimensão sintática, dimensão fônica, dimensão textual e dimensão enunciativa.

Atreladas ao ritmo da escrita, tais dimensões da pontuação evidenciam o que o autor chama de "aspecto multidimensional da linguagem". Nesse sentido, podemos afirmar que a vírgula tem, no texto, (i) funcionamento sintático, ao passo que delimita unidades linguísticas; (ii) funcionamento fonológico, relacionado a características prosódicas como pausas, contornos entoacionais, intensidade e duração; (iii) funcionamento textual, pois organiza porções textuais de forma a estabelecer a coesão textual e (iv) funcionamento enunciativo, relacionado ao posicionamento do sujeito frente a determinado assunto (CHACON, 1998; ESVAEL, 2005). Na construção do ritmo da escrita, a atuação das vírgulas por estas diferentes dimensões da linguagem se dá sempre em uma relação de alternância, motivo pelo qual "nenhum nível da linguagem pode requerer para si o fornecimento exclusivo de normas para o emprego da pontuação" (CHACON, 1998, p. 197). Consideramos a importância de todas as dimensões, porém, neste trabalho, fizemos um recorte metodológico a fim de investigar a atuação de vírgulas em textos do EFII em sua relação com as dimensões sintática e fônica da linguagem.

Subjacente a essa concepção de pontuação na qual nos ancoramos, assumimos, junto com Côrrea (2004), a noção de heterogeneidade constitutiva da escrita, uma vez que as vírgulas se constituem como marcas privilegiadas para a observação das relações entre enunciados falados e enunciados escritos. De acordo com o autor, não é possível dissociar os fatos sociais dos fatos linguísticos: os fatos sociais são também fatos de linguagem. Dessa forma, fala e escrita são práticas sociais de linguagem, impossíveis de serem dissociadas. Ao transitar por estas práticas, denominadas pelo autor como práticas orais/faladas e letradas/escritas, o sujeito da linguagem nos dá pistas acerca do caráter heterogêneo da escrita. Adotar tal perspectiva implica desconsiderar a noção de prosódia como acessória e/ou exterior à escrita e considerá-la como constitutiva do modo de enunciação escrito. Assim, nota-se um distanciamento de uma noção de escrita que prevê a interferência da relação fala e escrita e a adoção de uma noção teórica sobre escrita que prevê a ideia de constituição entre esses dois modos de enunciação. 
No que se refere à relação que ora buscamos estabelecer entre sintaxe e fonologia a partir dos empregos de vírgulas, adotamos a abordagem teórica da Fonologia Prosódica (NESPOR; VOGEL, 1986), que trata da interface sintaxefonologia. De acordo com as autoras, a fala é organizada em sete constituintes prosódicos: sílaba $(\sigma)$, pé métrico $(\Sigma)$, palavra prosódica $(\omega)$, grupo clítico $(C)$, frase fonológica $(\phi)$, frase entoacional (I) e enunciado fonológico (U). Todos os algoritmos de formação desses constituintes são definidos a partir da interface entre a fonologia e os componentes gramaticais - por exemplo, fonologia e sintaxe. Todavia, essa relação entre os componentes não é, necessariamente, de natureza isomórfica, haja vista que nem sempre há coincidência entre fronteiras prosódicas e fronteiras sintáticas de enunciados. De nossa perspectiva, essa é uma informação importante, pois a não coincidência entre essas fronteiras pode levar, por vezes, ao emprego não-convencional de vírgulas.

Em razão de nosso objeto de investigação se dar à nível sentencial ou oracional, três destes constituintes são relevantes para análise do emprego de vírgulas, conforme descrição feita por Tenani (2002) para o Português Brasileiro: a frase fonológica $(\phi)$, a frase entoacional (I) e o enunciado fonológico (U). De acordo com Nespor e Vogel (1986), a frase fonológica $(\phi)$ se configura no nível do sintagma e é delimitada pela união de dois ou mais grupos clíticos (C). Como exemplo, temos [chuva forte] $\phi$. A frase entoacional (I) se configura no nível da sentença e é delimitada pela união de duas ou mais frases fonológicas $(\phi)$, desde que essas apresentem contornos entoacionais: [Acho que vai chover hoje] I. Já o enunciado fonológico (U), por ser o constituinte mais alto da hierarquia, se configura no nível da sentença ou do período e é delimitado pela união de duas ou mais frases entoacionais $(\phi)$, como em [[Achei que ia chover,] I [mas me enganei] I] U.

Delimitado nosso arcabouço teórico, passamos à exposição do material selecionado e dos procedimentos utilizados na análise dos dados de vírgulas.

\section{Procedimentos metodológicos: material e critérios de análise}

Nesta pesquisa, o material selecionado para análise foi retirado do Banco de Dados de Escrita do Ensino Fundamental II, desenvolvido no âmbito de um projeto de extensão universitária da UNESP, credenciado e financiado pela Pró-reitoria de Extensão (PROEx) dessa universidade paulista (cf. detalhes em TENANI; LONGHINTHOMAZI, 2014). Os textos foram coletados ao longo dos quatro anos letivos do EFII e são resultado de oficinas de leitura e de escrita sobre diferentes gêneros e temas. Atualmente, o Banco de Dados, construído com apoio financeiro da FAPESP (Proc. 2013/14.564-5), conta com aproximadamente 5 mil textos. Ao total, selecionamos 188 textos, produzidos a partir de duas propostas textuais pelos mesmos 94 alunos em anos letivos diferentes - a saber, no $6^{\circ}$ e no $7^{\circ}$ anos letivos. As duas produções em questão diferem quanto ao tema ("Internet e o uso do MSN", no $6^{\circ}$ ano e "Brigas entre amigos", no $7^{\circ}$ ano), mas pertencem ao mesmo gênero e tipologia textual: carta pessoal/relato.

A justificativa para o estudo dos empregos de vírgulas no ciclo inicial do EFII está ancorada na tentativa de compreensão do uso e do funcionamento desse sinal de pontuação nas séries iniciais, haja vista informações observadas na Proposta Curricular 
do Estado de São Paulo (2008). Consta, nesse documento oficial, que o tema da pontuação - no qual nosso objeto de investigação se insere - não é tema central para os $6^{\circ}$ e $7^{\circ}$ anos. Logo, assumimos a hipótese de que o sujeito-escrevente, enquanto falante e aprendiz da escrita, emprega a vírgula com base em seus conhecimentos sobre possíveis relações entre a organização dos enunciados falados (particularmente, a organização prosódica) e a organização que vislumbra dos enunciados escritos (particularmente as regras de emprego de vírgula sobre as quais têm - ou não - algum tipo de conhecimento). Vale ressaltar que, de nossa perspectiva, os empregos de vírgulas parecem evidenciar, ao final dessa etapa de ensino, não apenas a organização que o sujeito vislumbra dos enunciados escritos, mas, de modo geral, uma organização dos fenômenos da linguagem. Independentemente do modo de enunciação, há uma tentativa de se inscrever em um contexto no qual as práticas letradas institucionais regulam o que deve ou não ser aceito em termos de linguagem.

Em relação à seleção das propostas do gênero carta pessoal, encontramos a informação também na Proposta Curricular do Estado de São Paulo (2008) de que no $6^{\circ}$ ano são trabalhados primordialmente textos narrativos e no $7^{\circ}$ ano, relatos de experiências. Considerando a disponibilidade de propostas realizadas nos anos de 2008 e 2009 do Banco de Dados, identificamos que a carta pessoal, tendo em vista o seu caráter de desenvolver uma narrativa ou um relato de experiências, era um dos gêneros que mais se relacionava com os tipos textuais que deviam ser trabalhados nos $6^{\circ}$ e $7^{\circ}$ anos.

No que se refere aos procedimentos metodológicos adotados para análise dos dados, fizemos, inicialmente, a identificação e a classificação das estruturas sintáticas a partir das regras prescritas por Bechara (1999) em sua Moderna Gramática Portuguesa. Concomitantemente à identificação e ao levantamento dessas estruturas, os dados foram classificados em convencionais e não-convencionais. Os usos convencionais referem-se aos empregos de vírgulas com base em um conjunto pré-estabelecido de regras gramaticais para usos de vírgulas. Os usos não-convencionais, por sua vez, subdividemse em: (i) usos não convencionais pela ausência - as vírgulas deixam de ser empregadas em contextos para os quais a convenção gramatical prevê seus usos - e (ii) usos nãoconvencionais pela presença - as vírgulas são empregadas, porém, em contextos não previstos pela tradição gramatical.

Salientamos o fato de que a seleção de uma gramática de referência está unicamente relacionada à forma de assegurar o diálogo com práticas escolares que se embasam nesse tipo de material, pois não temos como objetivo fazer uma análise normativa acerca dos empregos de vírgulas neste trabalho. Conforme argumentamos na seção de pressupostos teóricos, considerar os usos de vírgulas apenas na sua relação com a dimensão sintática é reduzir e limitar a observação do funcionamento complexo desse objeto. Portanto, partimos do levantamento de dados para analisar como a dimensão sintática em sua relação com a dimensão prosódica parecem atuar na ausência ou na presença de vírgulas.

Finalmente, levantadas as estruturas e os dados quantitativos de variável sintática, fizemos análise qualitativa de base prosódica com a finalidade de identificar e analisar quais fronteiras e/ou características prosódicas estariam associadas às fronteiras para as quais os usos de vírgulas foram observados. 


\section{Empregos de vírgulas no ciclo inicial do EFII: tendências e regularidades}

Nesta seção, apresentamos a descrição quantitativa dos empregos de vírgulas com base no levantamento sintático. Dos 188 textos analisados, obtivemos o total de 1.814 dados de usos de vírgulas. Desse total, como podemos ver ilustrado na Tabela 1, há predominância de empregos não-convencionais pela ausência em ambos os anos letivos (68,5\%), seguida dos usos convencionais $(26,4 \%)$ e dos usos não-convencionais pela presença $(5,1 \%)$. Quando somados, chegam a $73,6 \%$ os usos não-convencionais de vírgulas. Assim, podemos afirmar que uma das tendências encontradas para os textos do ciclo inicial do EFII é a frequência da não-convencionalidade dos empregos de vírgulas, especialmente em relação à ausência.

Tabela 1: Quantidade de empregos de vírgulas em função do ano letivo

\begin{tabular}{c|c|c|c}
\hline \multirow{2}{*}{ Usos de vírgulas } & \multicolumn{2}{|c|}{ Ano letivo } & \multirow{2}{*}{ Totais } \\
\cline { 2 - 3 } & $\mathbf{6}^{\mathbf{0}}$ ano & $\mathbf{7}^{\mathbf{0}}$ ano & \\
\hline Usos convencionais & 228 & 251 & 479 \\
\hline Usos não-convencionais pela ausência & 584 & 658 & 1242 \\
\hline Usos não-convencionais pela presença & 52 & 41 & 93 \\
\hline Totais & 864 & 950 & 1814 \\
\hline
\end{tabular}

A regularidade dos usos não-convencionais de vírgulas é informação importante porque nos remete à hipótese inicial de que a informação sintática não parece ser critério norteador dos usos de vírgulas para o período em questão, mas sim informações sobre a organização prosódica dos enunciados. Em outras palavras, queremos dizer que o aluno, ao desconhecer parcialmente ou totalmente as regras sintáticas para uso de vírgulas, ancora-se em informações linguísticas de ordem prosódica para empregar vírgulas. Procuraremos dar visibilidade maior a esta questão quando analisarmos prosodicamente os usos de vírgula na seção seguinte. Por ora, interessa-nos apresentar as tendências identificadas para os usos de vírgulas no ciclo inicial.

Foram levantadas também as estruturas sintáticas para as quais houve ocorrências dos usos de vírgulas. Na Tabela 2 abaixo, selecionamos as estruturas com maior número de ocorrências nos dois anos letivos para os usos convencionais e nãoconvencionais com o objetivo de fornecer um mapeamento das regularidades que caracterizam o uso de vírgulas no ciclo inicial do EFII ${ }^{1}$. Optamos por contrapor a frequência dessas duas categorias de usos - convencional versus não-convencional pela ausência - para as mesmas estruturas sintáticas porque ressaltamos, assim, algo que é corrente no ciclo inicial: a flutuação de empregos de vírgulas. Entendemos por flutuação a alternância entre empregos de vírgulas, para um mesmo contexto sintático, ora de modo convencional, ora não-convencional.

De nossa perspectiva, ainda que permaneçam os dados não-convencionais pela ausência de vírgulas para as estruturas em questão, a flutuação entre o convencional e o

\footnotetext{
${ }^{1}$ Se somados os totais dos usos convencionais e não-convencionais (ausência/presença) - cf. Tabelas 2 e 3 - das estruturas apresentadas neste trabalho, obtemos 1.471 ocorrências das 1.814 identificadas. Portanto, as estruturas selecionadas constituem mais da metade do total de dados (81\%, aproximadamente).
} 
não-convencional é resultado do conflito do sujeito escrevente da/na linguagem. Isso implica dizer que a recorrência da flutuação, nos textos do $6^{\circ}$ e dos $7^{\circ}$ anos letivos, pode ser resultado da tentativa do aluno em atender à convenção gramatical, de modo a se enquadrar nas expectativas da instituição escolar.

Como indícios da tentativa do aluno em inserir-se na prática institucional escolar, que prevê um conjunto de regras para usos de vírgulas, podemos considerar o aumento dos dados de um ano letivo ao outro: de 187 a 205 dados convencionais e de 474 a 562 dados não-convencionais. $\mathrm{O}$ aumento da frequência de uso convencional de vírgulas poderia ser interpretado como evidência de que os alunos estivessem identificando estruturas sintáticas que demandam usos de vírgulas, possivelmente devido à inserção do sujeito em práticas formais. No entanto, esse aumento de dados não implica, necessariamente, em emprego convencional, haja vista a quantidade de dados não-convencionais pela ausência - que também aumentam de um ano ao outro.

A respeito da Tabela 2, por fim, chamamos a atenção para a natureza das estruturas para as quais há dados de vírgulas. Para estruturas de natureza menos complexa, como "separar termos coordenados" ou "separar, nas datas, o nome do lugar", há predominância de usos convencionais. Em oposição, para estruturas de natureza mais complexa, que envolvem a noção de processos subordinativos, por exemplo, há predominância de usos não-convencionais pela ausência.

Tabela 2: Usos convencionais versus usos não-convencionais pela ausência

\begin{tabular}{l|c|c|c|c}
\hline \multirow{2}{*}{\multicolumn{1}{c}{ Estrutura Sintática }} & \multicolumn{3}{c}{ Tipo de emprego/ ano letivo } \\
\cline { 2 - 5 } & \multicolumn{2}{c}{$\begin{array}{c}\text { Dados } \\
\text { convencionais }\end{array}$} & $\begin{array}{c}\text { Dados não- } \\
\text { convencionais (ausência) }\end{array}$ \\
\cline { 2 - 5 } & $\mathbf{6}^{\mathbf{0}}$ ano & $\mathbf{7}^{\mathbf{0}}$ ano & $\mathbf{6}^{\mathbf{0}}$ ano & $\mathbf{7}^{\mathbf{0}}$ ano \\
\hline Separação de adjunto adverbial & 6 & 12 & 90 & 150 \\
\hline Separação de conjunção adversativa & 21 & 32 & 41 & 69 \\
\hline Separação de expressão de continuação & 2 & 17 & 47 & 81 \\
\hline $\begin{array}{l}\text { Separação de oração adverbial que vem antes ou } \\
\text { no meio de sua principal }\end{array}$ & 12 & 9 & 84 & 38 \\
\hline Separação de oração coordenada aditiva & 7 & 30 & 43 & 118 \\
\hline Separação de termos coordenados & 76 & 27 & 50 & 26 \\
\hline Separação de vocativo & 18 & 26 & 119 & 59 \\
\hline Separação, nas datas, do nome do lugar & 45 & 52 & 17 & 21 \\
\hline \multicolumn{1}{|c|}{ Totais } & $\mathbf{1 8 7}$ & $\mathbf{2 0 5}$ & $\mathbf{4 7 4}$ & $\mathbf{5 6 2}$ \\
\hline
\end{tabular}

Embora não seja nosso objetivo tratar de questões de gênero, não podemos ignorar o fato de que a ocorrência em número maior dessas estruturas em detrimento de outras pode estar associada ao gênero carta pessoal e aos temas das propostas. Assumimos, junto a Bakhtin (1992), que os gêneros são tipos relativamente estáveis, e, desse modo, condicionam o aparecimento de determinadas estruturas em detrimento de outras. Com relação à produção textual do $6^{\circ}$ ano, os alunos deveriam se projetar na figura de um personagem de quadrinhos, conhecido como Chico Bento, que vive em 
área rural, e dirigir-se, por meio da escrita de uma carta, a um suposto primo, residente da área urbana, para lhe perguntar sobre o funcionamento da internet e o modo de uso do aplicativo MSN. Dessa forma, o aparecimento de estruturas como "separar vocativo", "separar, nas datas, o nome do lugar" se justificam por fazer parte do estilo composicional do gênero carta pessoal e, por outro lado, o aparecimento da estrutura "separar termos coordenados" pode estar associado ao tema da proposta, em que os alunos deveriam enumerar o que era possível realizar por meio da internet e do MSN. $\mathrm{O}$ mesmo se aplica à proposta de carta pessoal do $7^{\circ}$ ano, na qual era solicitado aos alunos que escrevessem uma carta para um colega, relembrando quando tiveram uma briga e por quais motivos. É deste modo que estruturas como "separar adjunto adverbial", "separar expressão de continuação" ou "separar oração coordenada aditiva" ganham maior proporção devido à temática.

Por último, apresentamos as estruturas sintáticas que se destacam em termos de maior frequência de dados não-convencionais pela presença (cf. Tabela 3). Em oposição aos dados das categorias mencionadas anteriormente, os dados não-convencionais pela presença diminuem do $6^{\circ}$ para $07^{\circ}$ ano letivo. Ainda assim, não é possível estabelecermos um padrão quanto à frequência desse tipo de dado, em função de seu aumento, diminuição e flutuação em proporções muito próximas (cf. Tabela 1): a diferença entre um ano e outro é de apenas 11 ocorrências.

Tabela 3: Dados de usos não-convencionais pela presença

\begin{tabular}{l|c|c}
\hline \multirow{2}{*}{ Estrutura sintática } & \multicolumn{2}{|c}{$\begin{array}{c}\text { Usos não-convencionais } \\
\text { (presença)/ ano letivo }\end{array}$} \\
\cline { 2 - 3 } & $\mathbf{6}^{\mathbf{0}}$ ano & $\mathbf{7}^{\mathbf{0}}$ ano \\
\hline Separar adjunto adverbial em posição canônica & 7 & 6 \\
\hline Separar oração adverbial da oração principal & 6 & 4 \\
\hline Separar verbo do complemento & 14 & 6 \\
\hline Totais & $\mathbf{2 7}$ & $\mathbf{1 6}$ \\
\hline
\end{tabular}

De nossa interpretação, esse tipo de dado evidencia, de forma mais visível do que para os demais dados, o trabalho do sujeito com os sentidos do texto. Ao utilizar vírgulas para "separar advérbios", por exemplo, o aluno coloca em destaque um enunciado em relação ao que lhe é adjacente de modo que o efeito é dar pistas ao(s) seu(s) leitor(es) quanto à interpretação preferencial (ou que assim se apresenta) de seu texto. Como veremos adiante, a presença de vírgulas para esta categoria pode estar associada à delimitação, no texto escrito, de características como tom de fronteira, ou ainda, foco, destaque ou ênfase prosódica àquilo que se diz.

\section{Dados de vírgulas em uma produção escolar: indícios de características prosódicas}

$\mathrm{Na}$ seção anterior, fizemos um mapeamento das principais tendências e regularidades identificadas, em termos quantitativos, para os textos analisados dos alunos do $6^{\circ}$ e do $7^{\circ}$ anos letivos. Apresentamos também os contextos sintáticos em que 
houve uma frequência maior de dados de vírgulas. É importante destacar que não objetivamos nos limitar à análise sintática dos usos, mas sim considerar os dados anteriores para alcançarmos o objetivo central deste trabalho: fornecer evidências de características prosódicas associadas aos empregos de vírgulas. Isso só se torna possível, no entanto, se considerarmos o componente gramatical sintático, haja vista que a configuração do domínio prosódico só se dá na relação de interface com outro(s) componente(s) gramatical(is). No que diz respeito ao nosso objeto de análise, em específico, essa relação de interface se dá entre a sintaxe e a fonologia. O modo como se dá a relação entre os constituintes sintáticos é, de acordo com Nespor e Vogel (1986), informação relevante para análise das estruturas prosódicas.

Tendo isso em vista, selecionamos o texto abaixo (Figura 1), produzido no $6^{\circ}$ ano do EFII, para análise qualitativa. Como critério de seleção para análise neste artigo, optamos por trazer um dos textos que apresentassem recorrência e/ou flutuação de empregos de vírgulas, haja vista as regularidades apontadas na seção anterior.

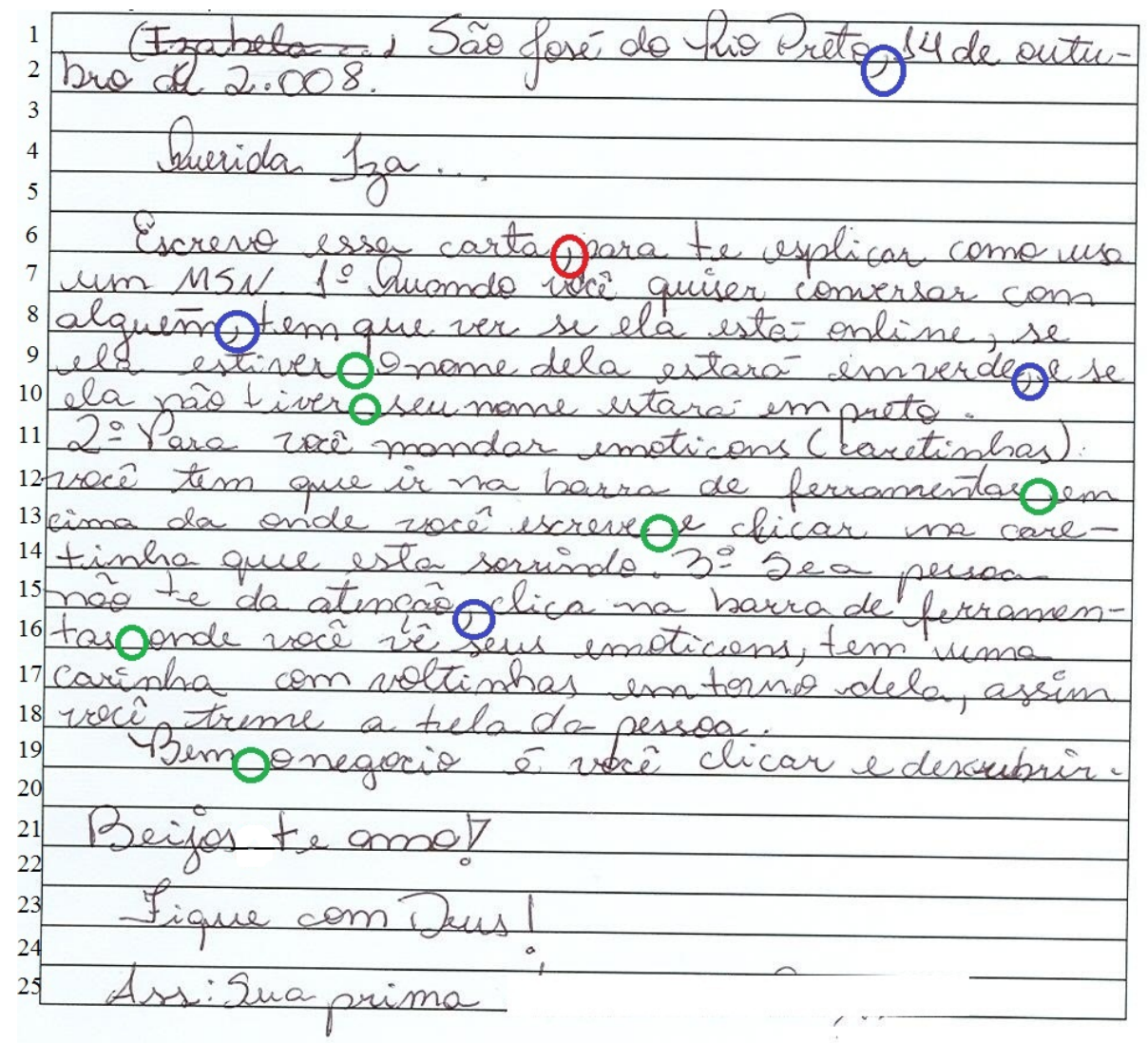

Figura 1. Texto Z08_5A_04F_04

Fonte: Banco de Dados de Escrita do EFII

Neste texto, observamos usos de vírgulas para todas as categorias com as quais trabalhamos ${ }^{2}$. Há usos convencionais para as estruturas: (i) Separar, nas datas, o nome do lugar, (ii) Separar oração adverbial que vem antes ou no meio de sua principal e

2 De forma a distinguirmos os usos, utilizamos diferentes cores para sinalizá-los. Os círculos azuis referem-se aos usos convencionais; os círculos verdes, aos não-convencionais pela ausência e o vermelho, não-convencional pela presença. 
(iii) Separar oração justaposta. Os usos não-convencionais pela ausência, por sua vez, são da seguinte natureza: (i) Separar oração adverbial que vem antes ou no meio de sua principal; (ii) Separar adjunto adverbial deslocado; (iii) Separar oração justaposta; (iv) Separar expressão de continuação e (v) Separar elemento extraoracional. Quanto ao único dado de uso não-convencional pela presença, identificamos (i) separação de oração adverbial em posição canônica. Há outros usos de vírgulas e/ou demais sinais de pontuação no texto. Acreditamos que essas ocorrências estão relacionadas a dados em que há troca de sinais de pontuação. A análise dos dados de troca não faz parte do escopo desta pesquisa. Para maior informação sobre ocorrências dessa natureza, indicamos o trabalho de Araújo-Chiuchi (2012).

Iniciamos a análise a partir do dado convencional de vírgula presente na primeira linha do texto. Para os empregos convencionais, no geral, observamos que I é a fronteira prosódica relevante para descrição desse tipo de dado de vírgula. Vemos que o sujeito delimita convencionalmente o nome do lugar: [São José do Rio Preto] I. A fronteira sintática para a qual a vírgula é utilizada coincide com uma fronteira prosódica de frase entoacional (I). Com base nos resultados obtidos por Tenani (2002), para o Português Brasileiro, as fronteiras de I de enunciados neutros são caracterizadas por possuírem tons de fronteiras. Esses tons, de acordo com a autora, podem ser pausas ou contornos entoacionais (ascendentes/descendentes). Dessa forma, interpretamos que a vírgula convencional se configura em uma fronteira de I onde um contorno entoacional do tipo descendente pode ser percebido. Portanto, a vírgula para este contexto indicia a possibilidade de identificação desse tom de fronteira de I.

Análise similar pode ser feita para o dado convencional de vírgula na linha 9. Consideremos a descrição prosódica deste dado: [[se ela estiver o nome dela estará em verde,] I [e se ela não tiver o nome dela estará em preto] I] U. A vírgula convencional é utilizada em um contexto para o qual há justaposição, ou ainda, a depender da gramática de referência, coordenação de orações. Desse modo, a vírgula em fronteira de I para este contexto evidencia novamente a mesma regularidade prosódica identificada para o dado anterior: trata-se de uma fronteira de I na qual tons podem ser atribuídos. A percepção da possibilidade de atribuição de tons de contornos entoacionais nessas fronteiras pode ser característica relevante para o uso convencional de vírgulas em fronteiras de I.

No entanto, esta análise não nos parece suficiente de ser realizada para os dados convencionais de vírgulas destacados nas linhas 8 e 15. Em ambos os contextos, temos estruturas de orações subordinadas adverbiais que precedem a oração principal. Vejamos como se dá a descrição prosódica de ambos os períodos e consideremos as fronteiras de usos de vírgulas das orações subordinadas adverbiais:

(01) [Quando você quiser conversar com alguém,] I [tem que ver se ela está online,] I

(02) [Se a pessoa não te da atenção,] I [clica na barra de ferramentas onde você vê seus emoticons,] I

Em ambos os exemplos, (1) e (2), estamos diante de fronteiras de Is não-finais neutras, diferentemente dos casos anteriores, em que as fronteiras de I se configuravam como finais e neutras. Atentar-se para essa questão é extremamente importante para interpretarmos a relação entre uso de vírgula e fronteira prosódica neste contexto. De 
acordo com Tenani (2002), quando temos uma sentença neutra, formada por mais de uma I - como nos casos acima - as Is não-finais dessa sentença são caracterizadas por um tom de fronteira nomeado pela autora como medial continuativo. Conforme explica Soncin (2012, p. 396), o que caracteriza esse tom medial continuativo é "um tom levemente ascendente (H\%) em fronteira de I" e também a possibilidade de ocorrência de pausa. Isso implica dizer que, para as estruturas [Quando você quiser conversar com alguém,] e [Se a pessoa não te dá atenção,], a vírgula convencional sinaliza uma fronteira com certo tom continuativo que dá a informação ao leitor de que a sentença não está finalizada, alguma informação ainda está por vir.

O leitor provavelmente deve ter notado que há, para a mesma estrutura analisada no parágrafo anterior, duas ocorrências de usos não-convencionais pela ausência de vírgulas nas linhas 9 e 10 do texto. Casos como este de flutuação são bastante típicos e caracterizam os empregos de vírgulas no EFII, conforme já argumentamos neste trabalho. Desse modo, como interpretaríamos essa ocorrência não-convencional para a mesma estrutura? Inicialmente, cabe a nós ressaltar que as fronteiras identificadas para os usos não-convencionais de vírgulas também estão relacionadas à I. Em outros termos, a ausência de vírgulas ocorre onde supostamente deveria haver a identificação de fronteiras de I. Vejamos abaixo, para os mesmos enunciados, como seria a leitura caso houvesse a presença convencional da vírgula e como ela é, de fato, com a ausência de vírgula:

(03) [se ela estiver,] [o nome dela estará em verde,] I

(04) [se ela estiver o nome dela estará em verde] I

(05) [se ela não tiver,] I [seu nome estará em preto] I

(06) [se ela não tiver seu nome estará em preto] I

A interpretação que fazemos para a ausência de vírgulas em fronteira de I nestes dados pode estar associada à possibilidade da reestruturação de Is. De acordo com Nespor e Vogel (1986), a reestruturação de Is é mais provável de ocorrer quando há o seguinte cenário para as estruturas: (i) extensão relativamente longa de I, (ii) velocidade relativamente lenta de fala e (iii) maior formalidade de registro. Além disso, para as autoras, esse processo só é passível de ocorrer entre as fronteiras e nunca entre sintagmas. Frota (2000) também destaca a dimensão e a complexidade prosódica como fatores importantes para que haja a reestruturação de Is. Dessa forma, as Is [se ela estiver] I e [se ela não tiver], sintática e prosodicamente menos complexas, são reestruturadas à [o nome dela estará em verde] I e [seu nome estará em preto], respectivamente, porque estas são mais longas e sintaticamente mais complexas. Como resultado, temos a ausência de vírgulas nessas fronteiras, pois, diante da identificação da possibilidade de reestruturação, as Is de menor complexidade prosódica são agrupadas às Is de maior complexidade prosódica e ambas passam a configurar apenas uma I, como descrito em (4) e (6). 
As demais ocorrências de usos não-convencionais pela ausência de vírgulas também foram analisadas como resultado da probabilidade de reestruturação de Is. Para o dado de adjunto adverbial deslocado, nas linhas 12 e 13, acreditamos que a estrutura em questão - [em cima da onde você escreve] - possui menor complexidade sintática e prosódica, sendo, portanto, incorporada às Is adjacentes, que, em termos sintáticos e prosódicos, são de maior complexidade, conforme pode ser observado em (7). Para as estruturas em (8) e (9), os casos de ausência de vírgulas também indiciam possibilidades de reestruturação de Is, haja vista que as Is, para as quais deveriam haver vírgulas, ocorrem em domínios em que é possível haver reestruturação e, portanto, são agrupadas às demais Is que lhes são adjacentes.

(07) [ [você tem que ir na barra de ferramentas em cima da onde você escreve e clicar na caretinha que está sorrindo] I] U

(08) [clica na barra de ferramentas onde você vê seus emoticons] I

(09) [Bem o negócio é você clicar e descubrir] I

Finalmente, passamos à análise do dado não-convencional pela presença de vírgula, sinalizado na linha 6 do texto. Em grande parte dos contextos para os quais houve esse tipo de dado, a fronteira associada à vírgula foi de $\phi$. Nesse tipo de fronteira, identificamos que o uso de vírgulas funcionava enquanto marca de focalização, destaque ou ênfase dos elementos em uma sentença, a depender de onde a fronteira era identificada. Para outra parte dos dados, no entanto, as vírgulas foram inseridas em fronteiras de I, como é o caso do exemplo em (10). Além de as fronteiras de Is estarem relacionadas a determinados tons (pausas, contornos entoacionais), conforme buscamos exemplificar em exemplos anteriores, a ênfase prosódica também é evento tonal relacionado à fronteira de I. A nossa interpretação para o dado em (10), desse modo, é de que a vírgula é empregada justamente onde tal ênfase prosódica pode ser percebida. Isso implica dizer que a vírgula em [escrevo esta carta,] configura um certo contorno focalizador que dá a direção, em termos semânticos, de como a informação que vem na sequência deve ser interpretada. Ao utilizar vírgulas nessa fronteira, o sujeito focaliza, para o leitor, aquilo que pretende fazer na carta: explicar como se usa o MSN.

(10) [Escrevo esta carta,] I [para te explicar como usa um MSN.] I] U

Todos os dados do ciclo inicial que ora apresentamos expressam, de nossa perspectiva, o modo como os usos de vírgulas evidenciam a circulação do sujeito por práticas escritas e práticas orais. A partir das representações do que seja fala e do que seja escrita, o sujeito-escrevente se ancora naquilo que conhece de características dos enunciados falados para construir seu texto escrito. Essa projeção do falado/escrito, no entanto, não é da ordem da transposição ou da interferência, mas sim de natureza constitutiva, haja vista que não é possível dissociar a fala da escrita. 


\section{Considerações finais}

Neste artigo, por meio da análise dos empregos de vírgulas em um texto produzido no ciclo inicial do EFII, objetivamos demonstrar a relação que ora propomos entre sinais de pontuação e características prosódicas de enunciados falados. Cabe enfatizar que não concebemos os empregos de vírgulas como marcas da transposição entre fala e escrita, mas sim enquanto "sinal de pontuação que, embora sendo gráfico, é marca linguística de processos simbólicos que se efetivam na escrita por meio da relação com a oralidade, particularmente pelo domínio prosódico" (SONCIN; TENANI, 2015). Desse modo, apresentamos (i) as principais características de distribuição de empregos de vírgulas para o ciclo inicial do EFII e (ii) as relações observadas entre usos de vírgulas e fronteiras de domínios prosódicos, particularmente no que diz respeito ao domínio de frase entoacional (I).

Embora esta pesquisa seja pautada pela análise e descrição linguística do nosso objeto de investigação, os resultados podem gerar contribuições para profissionais do EFII que lidam com a linguagem em sala de aula. Especificamente, nos referimos aos professores de Língua Portuguesa desse contexto escolar. Ao considerarmos que os dados de vírgulas sejam observados enquanto processo e não produto do trabalho do sujeito com dimensões da linguagem, propormos um olhar teórico-metodológico para estes empregos que vão além da classificação normativa feita pela instituição escolar entre "erro" e "acerto".

\section{Agradecimentos}

Agradeço à professora Dra. Luciani Ester Tenani pela orientação desta pesquisa. As considerações trazidas neste artigo são resultado de sua supervisão cuidadosa. Agradeço também à FAPESP pelo auxílio financeiro.

\section{REFERÊNCIAS}

ARAÚJO-CHIUCHI, A. C. Os usos não-convencionais da vírgula em textos de alunos da quinta série do Ensino Fundamental. 2012. 91 f. Dissertação (Mestrado em Análise Linguística) -Instituto de Biociências, Letras e Ciências Exatas, Universidade Estadual Paulista “Júlio de Mesquita Filho”, São José do Rio Preto, 2012.

BAKHTIN, M. Estética da criação verbal. São Paulo: Martins Fontes, 1992.

BECHARA, E. Moderna Gramática Portuguesa. 37. ed. Rio de Janeiro: Lucerna, 1999.

CHACON, L. Ritmo da escrita: uma organização do heterogêneo da linguagem. São Paulo: Martins Fontes, 1998.

CÔRREA, M. L. G. O modo heterogêneo de constituição da escrita. São Paulo: Martins Fontes, 2004.

DAHLET, V. As (man)obras da pontuação: usos e significações. São Paulo: Associação Editorial Humanitas, 2006. 
ESVAEL, E. V. S. Pontuação na escrita de universitários: a função enunciativa da vírgula. 2005. 124 f. Dissertação (Mestrado em Letras) - Faculdade de Filosofia, Letras e Ciências Humanas, Universidade de São Paulo, São Paulo, 2005.

FROTA, S. Prosody and focus in European Portuguese. 1998. 440 f. Tese (Doutorado em Linguística) - Faculdade de Lisboa, Universidade de Lisboa, Lisboa, 1998. (Publicado por Garlang Publishing - series Outstanding Dissertations on Linguistics. New York/London, 2000.)

NESPOR, M.; VOGEL, I. Prosodic Phonology. Dordrecht-Holland: Foris Publications, 1986.

PROPOSTA CURRICULAR DO ESTADO DE SÃO PAULO: Língua Portuguesa. Coord. Maria Inês Fini. São Paulo: Secretaria Estadual de Educação, 2008. Disponível em:

$<$ www.rededosaber.sp.gov.br/portais/Portals/19/arquivos/Prop_LP_COMP_red md 20 03.pdf>. Acesso em: 20 ago. 2017.

SONCIN, G. C. N. As vírgulas não-convencionais em textos dissertativos produzidos em ambiente escolar: indícios de organização prosódica, evidências dos imaginários sobre a escrita. Estudos Linguísticos, São Paulo, v. 41, n. 2, p. 389-402, 2012.

SONCIN, G.; TENANI, L. Emprego de vírgula e prosódia do Português Brasileiro: aspectos teórico-analíticos e implicações didáticas. Filologia e Linguística Portuguesa, v. 17, n. 2, p. 473-493, 2016.

TENANI, L. E.; LONGHIN THOMAZI, S. R. Oficinas de leitura, interpretação e produção textual no ensino fundamental. Revista em Extensão (on-line), v. 13, p. 20-34, 2014. Disponível em: <www.seer.ufu.br/index. php/revextensao/article/viewFile/27049/14678>. Acesso em: 20 ago. 2017.

. Banco de Dados de Escrita do Ensino Fundamental II. Disponível em: <http://www.convenios.grupogbd.com/redacoes/Login>. Acesso em: 20 ago. 2017.

. Domínios prosódicos no Português do Brasil: implicações para a prosódia e para a aplicação de processos fonológicos. 2002. 317 f. Tese (Doutorado em Linguística) - Instituto de Estudos da Linguagem, Universidade Estadual de Campinas, Campinas, 2002.

Recebido em: 22/09/2017

Aprovado em: 24/11/2017 